University of Rhode Island

DigitalCommons@URI

Open Access Dissertations

1991

\title{
Validity of Tasks of Executive Functions with School-Aged \\ Children: Potential Efficacy in Discriminating Clinical Groups
}

Lisa L. Weyandt

University of Rhode Island

Follow this and additional works at: https://digitalcommons.uri.edu/oa_diss

\section{Recommended Citation}

Weyandt, Lisa L., "Validity of Tasks of Executive Functions with School-Aged Children: Potential Efficacy in Discriminating Clinical Groups" (1991). Open Access Dissertations. Paper 940.

https://digitalcommons.uri.edu/oa_diss/940

This Dissertation is brought to you for free and open access by DigitalCommons@URI. It has been accepted for inclusion in Open Access Dissertations by an authorized administrator of DigitalCommons@URI. For more information, please contact digitalcommons-group@uri.edu. 


\section{VALIDITY OF TASKS OF EXECUTIVE FUNCTIONS WITH SCHOOL-AGED CHILDREN:

\begin{abstract}
POTENTIAL EFFICACY IN DISCRIMINATING
\end{abstract} \\ CLINICAL GROUPS}

BY

LISA I WEYANDT

A DISSERTATION SUBMITTED IN PARTIAL FULFILLMENT OF THE REQUIREMENTS FOR THE DEGREE OF DOCTOR OF PHILOSOPHY

IN

PSYCHOLOGY

UNIVERSITY OF RHODE ISLAND

1991 


\section{Abstract}

The purposes of the present study were (a) to investigate the performance of three groups of children, those diagnosed with Attentiondeficit Hyperactivity Disorder, those diagnosed with Developmental Language Disorder, and a matched group of nondisabled children on a battery of neuropsychological tasks purported to measure executive function, and (b) to investigate the validity of tasks used to measure executive function across three age levels. A double-dissociation paradigm was used. Six executive function tasks and two nonexecutive function (i.e., vocabulary) tasks were administered to all participants in a counterbalanced order. Results revealed significant group and age effects. Significant differences were found between groups on three executive function measures, with the nondisabled group differing from the two clinical groups on two of the executive function measures, and the clinical groups differing on one executive function measure. Additionally, results revealed significant differences between the Language Disorder group and the other two groups on the two nonexecutive function measures. The relationships between age and all measures were linear. Collectively, the results did not provide evidence of a clear double dissociation suggesting that deficits in executive functions may not be specific to ADHD. Theoretical and clinical implications were discussed in terms of executive functioning in child clinical populations, and suggestions for future research were advanced. 
I would like to express my deepest gratitude to my major professor w. Grant willis whose guidance, support, and brilliance helped make this dream a reality. Dr. Willis was always available to listen, advise, and perhaps most importantly, to boost my confidence when completion of this dissertation seemed an insurmountable task.

Secondly, I would like to thank the members of my committee who provided valuable feedback and insight regarding the design, analysis, and interpretation of the study. I am particularly grateful to Dr. Joseph Rossi, who generously provided statistical and computer assistance for hours on end. Dr. Janet Kulberg I owe thanks for motivating me to design and propose the study within a relatively short period of time. Dr. Dominic valentino I would like to thank for always making time, even on a moments notice to discuss practical and theoretical aspects of the study. Drs. Dayle Joseph and Boulmetis deserve special recognition for being graciously accommodating.

Next I would like to express my deepest appreciation to Dr. Louise Kiesling, Dr. George Dupaul, the school systems throughout Rhode Island, the parents, and most importantly, to all of the children who unselfishly contributed their time and energy to this project.

I would also like to thank my friends who have seen me through the difficult times, particularly Sarah Cilano, Frederick and Paal Mowinckel, Catherine Walsh, and most notably Bradford E. Arnold.

Lastly, I would like to express my appreciation to my family, who has supported me in many ways throughout the years. I am particularly grateful to my mother who has always believed in me. 


\section{Preface}

This manuscript was prepared under the manuscript thesis plan according to the Publication Manual of the American Pgychological Association (1983) guidelines. 
Abstract - . . . . . . . . . . . . . . . . . . . . . . . i

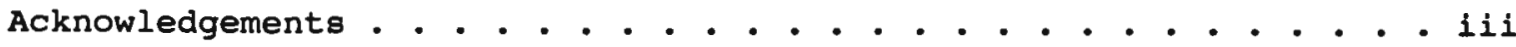

Preface . . . . . . . . . . . . . . . . . . . . . . . . . . iv

List of Tables . . . . . . . . . . . . . . . . . . . . . . . . vi

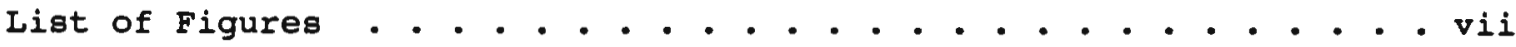

Chapter

I. Introduction . . . . . . . . . . . . . . . . . . . . . 1

Investigations of Executive Functions in Children . . . . . 2

Clinical Populations . . . . . . . . . . . . . . . . . 3

Summary •. • . . . . . . . . . . . . . . . . . . . . . 7

Double Dissociation Paradigm . . . . . . . . . . . . . . . 7

Purpose of the Research . . . . . . . . . . . . . . . 8

II. Method . . . . . . . . . . . . . . . . . . . . 10

Subjects . . . . . . . . . . . . . . . . . . . . . . . 10

Procedure . . . . . . . . . . . . . . . . . . . . . . 11

Tasks . . . . . . . . . . . . . . . . . . . . . 11

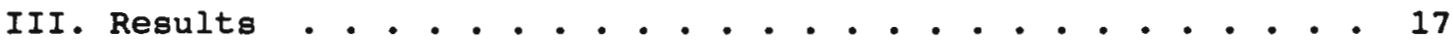

Follow-up Tests . . . . . . . . . . . . . . . . . . . 21

Discriminant Function Analysis . . . . . . . . . . . . . . 23

IV. Discusgion . . . . . . . . . . . . . . . . . . . . 29

Group Differences - . . . . . . . . . . . . . . . . . 29

Age-related Changes . . . . . . . . . . . . . . . . . . 31

Discriminant Analysis . . . . . . . . . . . . . . . . . 33

Double Disgociation . . . . . . . . . . . . . . . . . 34

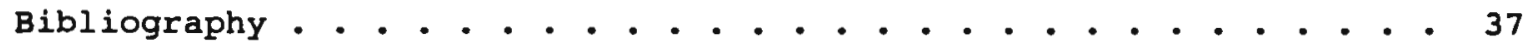


1. Means and Standard Deviations for Nondisabled and clinical

Groups . . . . . . . . . . . . . . . . . . . . . . 18

2. ANOVA Table for Peabody Picture Vocabulary Test-Revised ..$~ 19$

3. ANOVA Table for Boston Naming Test . . . . . . . . . . . . 19

4. ANOVA Table for Matching Familiar Figures Test-Errors . . . 19

5. ANOVA Table for Mazes . . . . . . . . . . . . . . . 20

6. ANOVA Table for Tower of Hanoi . . . . . . . . . . . . . . . 20

7. Means and Standard Age Groups I, II, and III . . . . . . . 22

8. Structure Matrix of Correlations Between Predictor Variables and Discriminant Functions . . . . . . . . . . . . . . . . 27

9. Classification Accuracy Table . - . - . . . . . . . . . . . 28 
1. Conceptual overview of group performance on executive function and nonexecutive function tasks

2. Discriminant functions distinguishing between children with $A D H D$ and language disorder, and between nondisabled and clinical groups. 
Chapter 1

Introduction

The frontal lobes of the brain have been of interest to psychologists and neuroscientists for decades, yet remain one of the least understood regions of the brain (Nauta, 1971). A plethora of investigations has examined frontal lobe functioning in both primates and humans. This research has been conducted at neuroanatomical (e.g., Goldman \& Nauta, 1977; Pandya, Dye, \& Kuppers, 1971), neurophysiological (e.g., Fuster, 1973; Niki, 1974), and behavioral (e.g., Goldman-Rakic, Isseroff, Schwartz \& Bugbee, 1983; Luria, 1973, Stuss \& Benson, 1984) levels of analysis.

The preponderance of empirical information about frontal lobe functioning in humans, however, derives mainly from behavioral level research involving neuropsychological studies of adults who have sustained frontal lobe damage (Luria, 1972; Stuss \& Benson, 1984). specific neuropsychological deficits that have been ascribed to frontal lobe damage include a poor self-control, disinhibition, emotional lability, impulsivity, poor planning ability, and perseveration (Beaumont, 1983; Lezak, 1983; Luria, 1966). The capabilities that enable an individual to control these behaviors and to engage in purposeful goal-directed behavior have been identified as executive functions (Goldberg, 1986; Lezak, 1983; Luria, 1972). Executive functions are thought to facilitate future-oriented problem solving behavior by allowing for inhibition, strategic planning, and flexibility of thought and action. Clinical evidence suggests that executive functions may be subserved by the prefrontal anterior cortical regions of the brain, which are believed to be involved in the modulation of behavior through selective attention, organization, and integration of information (Becker, Isaac, \& Hynd, 1987).

Despite the psychoeducational implications of executive functions, relatively little information currently is available about the nature of 
these cognitive processes in children. Further, the ontogeny of executive functions remains equivocal. Luria (1973), for example, proposed that these processes do not emerge until the prefrontal cortex matures between the ages of four and seven years. In contrast, Golden (1987) asserted that prefrontal areas do not begin to develop until late adolescence, and continue to mature until early adulthood (i.e., around age 24). More recently, Welsh and Pennington (1988) argued that executive functions emerge during the first year of life and continue to develop throughout pubescence and possibly into adulthood.

Invertigations of Executive Functions in Children

As Welsh and Pennington (1988) have noted, research in developmental psychology indirectly has studied executive functions through areas of investigation such as the development of self-control, problem solving ability, and selective attention. For example, Diamond and Goldman-Rakic (1987), using a Piagetian object-permanence paradigm, found evidence of anticipation and planning in infants, as well as impulse control and goal-oriented behavior in toddlers. Similarly, RopP (1982) investigated the development of Belf-control behavior (i.e., ability to inhibit inappropriate responding) and concluded that the ability to regulate one's own behavior follows a protracted period of development extending from infancy into adulthood. Further, research on problem-solving skills suggests that the ability to generate problem solving atrategies (i.e., plans) improves from preschool age throughout adolescence (Becker \& Pennington, 1988).

Passler, Isaac, and Hynd (1985) were among the first to attempt to investigate empirically executive functions from a neuropsychological perspective. Uoing a cross-sectional design, the performance of 44 children, between the ages of 6 and 12 years, was investigated using tasks purported to measure prefrontal functioning in adults. Results demonstrated greateat performance gains between ages 6 and 8 years, with mastery of tasks generally evident by age 12 years. 
Similar results were found by Becker, Isaac, and Hynd (1987) in an investigation of age-related changes in the ability of children to inhibit and to regulate motor action on various neuropsychological measures. Consistent with Passler (1985), results suggested an early emergence of, and age-related change in, behaviors putatively subserved by the prefrontal lobes.

Additionally, Welsh, Pennington, and Grossier (in press) conducted a cross-sectional, normative study of 100 children aged 3 to 12 years, using a battery of neuropsychological measures purported to assess executive functions in children (Matching Familiar Figures Test, Motor Sequencing, Tower of Hanoi, Verbal Fluency, Visual Search, and wisconsin Card sorting Test). Results were consistent with Passler et al. (1985) and with Becker et al. (1987), suggesting an early emergence of executive functions that appear to follow a stage-like course of development. Longitudinal atudies, of course, are required to evaluate this hypothesis more fully.

Finally, Gnys and willis (in press) used a multitrait-multimethod paradigm to assess the stability, discriminant validity, and convergent validity of two commonly used tasks of executive function (i.e., Verbal Fluency and Tower of Hanoi). Participants were 96 preschool and kindergarten-aged children enrolled in regular educational classrooms. Contrary to expectations, results did not fully support the construct validity of Verbal Fluency and Tower of Hanoi as measures of executive function, thereby raising questions about the psychometric properties of these particular tasks.

\section{Clinical Populations}

Executive functions also have been examined for child clinical samples. Welsh, Pennington, Oznoff, Rouse, and McCabe (1987), for example, explored the hypothesis that young children with early-treated phenylketonuria (PKU) would evidence impairments on a battery of tasks (e.g., Visual Search, Verbal Fluency, Motor Planning, and Tower of 
Hanoi) thought to measure executive functions in children. It was proposed that prefrontally mediated behaviors might be impaired, given the pathophysiology of PKU. Results supported this hypothesis and indicated that, despite aimilar intellectual aptitudes, the PKU children demonstrated significant impairments on executive function tasks relative to normal controls.

Behaviors associated with prefrontal lobe functioning also have been implicated in children with Attention-deficit Hyperactivity Disorder (ADHD). Although the pathophysiology of ADHD is not well understood, several theories implicating prefrontal lobe deficits have been postulated. Wender (1971) for example, asserted that ADHD involves diminished catecholamine activity in the caudate nucleus and, given the projections to the prefrontal cortex, hypothesized prefrontal dysfunction in ADHD children. An alternative (but not contradictory) theory proposed by Satterfield and Cantwell (1975) Implicated a dysfunctional reticular activity system and an associated decreased cortical arousal. Mattes (1980) theorized that the dopaminergic pathways in the frontal lobea may be dysfunctional in ADED. Additionally, Mattes (1980) was among the first to provide an analogy between the behavioral symptoms associated with ADHD, and those behaviors associated with frontal lobe dysfunction in adults. Others (e.g., Denkla, 1978; Hudson, 1991; and Voller, 1986) also have implicated frontal lobe dysfunction in ADHD.

Neurophysiologically, preliminary evidence exists to support the prefrontal dysfunction hypothesis of ADHD. Lou, Henricksen, and Bruhn (1984), for example, conducted an investigation involving computer mapping of regional cerebral blood flow (rCBF) in children with ADHD, compared to a group of control children. Results indicated that children with ADHD, relative to controls, showed hypoperfusion (bilaterally) in the white matter of the frontal lobes. Seven of the eleven ADHD children also showed hypoperfusion in the region of the 
caudate nucleus. Treatment with methylphenidate (MPH) resulted in increased blood flow bilaterally in the basal ganglia and mid-brain, as well as decreased perfusion in the primary sensory regions of the occipital and temporal lobes. Behaviorally, children evidenced improved attention and impulse control, and decreased motor activity. Considering the hypothesized pharmacological action of MPH, results appeared to provide supportive evidence of frontal lobe involvement in ADHD.

Zametkin and Cohen (1990), using positron emission tomography (PET), examined adults with childhood onset of ADHD, and found decreased global and regional (i.e., prefrontal areas) glucose metabolism in this clinical sample relative to controls. Hynd and semrud-clikeman (1990) examined magnetic resonance imaging (MRI) scans of eight children with $A D H D$, and found that children with ADHD, relative to controls, had smaller right frontal areas, shorter right insular region lengths, and smaller regions of the corpus callosum (i.e., genu and splenium). Results were interpreted as lending credence to the view that the neural networks subserving behaviors of motor regulation, persistence, and inhibition of children with ADHD differ from children without ADHD symptomotology.

Neuropsychologically, results of preliminary investigations appear to support interpretations of anatomical and physiological data implicating the prefrontal lobes in ADHD. Chelune, Ferguson, Koon, and Dickey (1986), for example, investigated the performance of children diagnosed with ADHD and a group of matched controls on several tasks (e.g., Wisconsin Card Sorting Test, Progressive Figures, and Color Forms) found to be sensitive to frontal lesions in adults. Results revealed gignificant group and age differences. Children with ADHD performed significantly more poorly than controls, and overall task performance was found to improve as a function of age. A discriminant 
function analysis resulted in an accurate classification rate of 85 percent.

Similar results were reported by Boucugnani and Jones (1989) who investigated the performance of 28 children diagnosed as ADHD and 28 normal controls on the Wisconsin Card Sorting Test, Trail-Making Test Part B, and Stroop Color and Word Test. Consistent with chelune et al. (1986), significant group and age differences were found. Children with ADHD performed significantly more poorly than control children on Wisconsin Card Sorting Test, Trail Making Test, and Stroop Color and Word Test. A discriminant function analysis revealed an overall correct classification rate of 79 percent.

McGee, Williams, Moffitt, and Anderson (1989) examined the performance of adolescent boys with $\mathrm{ADHD}$ and/or reading disorder, and controls on several neuropsychological measures including three tasks (Mazes, Wisconsin Card Sorting Test, and Trail-Making Test) thought to measure prefrontal functioning in adults. Contrary to expectations, no significant differences were found between groups. Fischer, Barkley, Edelbrock, and Smallish (1990) reported similar findings in a follow-up study of 100 adolescents with ADHD. No significant group differences were found between children with ADHD and a matched comparison group on the Wisconsin Card Sorting Test, Controlled Oral Word Association Test, and Matching Familiar Figures Test (adolescent version). A significant main effect for age was found, however, on the Wisconsin card sorting Test (errors).

Welsh, Wall, and Towle (1989) investigated the performance of children with ADHD compared to a group of matched clinical controls (children with Developmental Language Disorder) on three tasks from an executive function battery; a discriminant function analysis assigned group membership with 92 percent accuracy. A significant limitation of the study, however, was that a language measure was not included. The inclusion of a language measure might have provided valuable information 
about the discriminant validity of the tasks as measures of executive function.

Summary

Collectively, results from preliminary neurophysiological, limited neuranatomical and several neuropsychological studies appear to provide support for the hypothesis that executive functioning, putatively ascribed to the prefrontal regions, are present at an early age, continue to develop throughout childhood, and may not mature until early adolescence. Results are equivocal, however, about whether child clinical samples differ from controls on tasks purported to measure executive functions. clearly, additional research is needed to establish more fully the construct of executive functioning, and to evaluate the validity of tasks that generally have been extrapolated from adult-based literature. Certainly, the practice of using scaleddown versions of adult assessment tools is, at best, tenuous. As Fletcher (1984) elucidated, the assumptions (a) that procedures used with adults are differentially sensitive to brain dysfunctions in children, and (b) that behavioral tests developed for adults measure the same abilities in children, are not necessarily valid. Thus, it is important that tasks that are thought to measure prefrontal functioning in adults be established independently as reliable and valid as valid and reliable measures for use with children. Double Dissociation Paradigm

In order to establish the validity of these kinds of tasks, it also is important to address the issue of clinical utility. Here, not only is it important to show that a task differentiates clinical from nonclinical populations, but also that the task effectively discriminates among various clinical populations. This issue can be addressed through a group application of a paradigm known as double dissociation. 
Jones (1983) emphasized the theoretical importance of the doubledissociation paradigm in demonstrating the existence of neurologically distinct functional systems. According to Jones, a double dissociation occurs when two different lesion sites result in differential deficits in task performance. Thus, Lesion $A$ would regult in poor performance on Task I but not on Task II, whereas Lesion B would result in poor performance on Task II but not on Task I. This double-dissociation paradigm can be extended from a lesion-deficit analyois to a behavioralimpairment-clinical-group analysis in order to help establish the validity and clinical utility of neuropsychological tasks for use with children. For example, if two clinical groups of children were tested on tasks believed to measure their associated impairments, reaults should indicate a behavioral impairment of clinical Group A (e.g., ADHD) on Task I, but not on Task II. Likewise, Clinical Group B (e.g., Developmental Language Disorder) should demonstrate a behavioral impaiment on Task II but not on Task I, thereby providing aupportive evidence that the tasks are measuring two distinct constructs. Moreover, to provide evidence that Task $I$ is a valid measure of its associated construct (e.g., executive function), Task I should correlate better with a task designed to measure the same construct, than with a nonexecutive function measure.

\section{Purpose of the Research}

The purposes of the present study were (a) to investigate the performance of three groups of children, those diagnosed with ADHD, those diagnosed with Developmental Language Disorder, and a nondisabled group of matched comparison children on a battery of neuropsychological tasks purported to measure executive functions, and (b) to investigate the construct validity of taskg used to measure executive function at three age levels. A double-dissociation paradigm was used and children with Developmental Language Disorder comprised the clinical comparison group. Selection of neuropsychological tasks, as well as selection of 
the clinical comparison group was based on their use in previous neuropsychological investigations. It was predicted that:

1. The ADHD group would perform more poorly than the Language Disordered group or the nondisabled group, across all eight measures of executive function.

2. The Language Disordered group would perform more poorly than either the ADHD group or the nondisabled group on the two nonexecutive function measures (i.e., vocabulary).

3. Group performance would reflect age-related change日 in executive function performance with all three groups evidencing improved performance with increasing age.

4. A linear component representing the eight executive function measures and two nonexecutive function measures would discriminate among the ADHD, Language Disordered and, nondisabled groups. 
Chapter II

Method

Subjects

Participants consisted of three groups of children: 36 white males with Attention-deficit Hyperactivity Disorder (ADHD) ( $\underline{M}$ age = 108.2 months, $\underline{\text { D }}$ age $=29.76$ months), 34 white children with

Developmental Language Disorder (American Psychiatric Association, 1987) ( 18 males and 16 females, $\underline{M}$ age $=102.67$ months, $\underline{S D}$ age $=22.8$ months), and 45 white comparison children $(24$ males and 21 females, $\underline{M}$ age $=108$ months, $\underline{\text { SD }}$ age $=21.08$ months) enrolled in regular education classrooms in the state of Rhode Island. All of the children were right-handed as determined by the hand used to write their name.

children with ADHD met the following inclusion criteria: (a) a diagnosis by the child's pediatrician or psychologist using the Diagnostic and Statistical Manual of Mental Disorders Third edition, Revised (DSM III-R) criteria for ADHD (American Psychiatric Association, 1987); (b) a teacher rating of at least one standard deviation above the mean on the Revised Conners Teacher Rating Scale (Goyette, Conners, \& Ulrich, 1978), (c) a maternal rating of at least one standard deviation above the mean for the child's age on the Revised Conners Parent Rating Scale (Goyette et al., 1978), (d) a maternal endorsement of at least 8 of the 14 items on the ADHD Rating Scale (DuPaul, 1990), (e) average to above average intelligence as assessed by the Raven's Coloured Progressive Matrices (Raven, 1965), (f) currently enrolled in a regular education classroom.

Children with Developmental Language Disorder met the following inclusion criteria: (a) a diagnosis of Developmental Language Disorder (both Receptive and Expressive types) by the school's speech and language therapist; (b) average to above average intelligence as assessed by the Raven's Coloured Progressive Matrices (Raven, 1965); and (c) enrollment in a regular education classroom with special education 
services for language therapy only.

Nondisabled children met the following inclusion criteria: (a) average to above average intelligence as assessed by the Raven's Coloured Progressive Matrices (Raven, 1965); (b) enrollment in a regular education classroom and (c) experiencing no learning or behavioral difficulties as reported by the classroom teacher.

Written permission was obtained for all children. A total of eight children scored below the fiftieth percentile on the Raven's Coloured Progressive Matrices (Raven, 1965) and were excluded from the study. Treatment of participants was in accordance with ethical standards suggested by the American Psychological Association (APA, 1981) and the University of Rhode Island's Institutional Review Board for research with human subjects.

\section{Procedure}

To control for possible medication effects, children with ADHD ceased medication at least 24 hours prior to participation in the study. Twenty-four hours was considered ample time for washout of the drug, considering the short half-life (approximately four hours) of methylphenidate. Twenty-two of the 36 ADHD children were taking stimulant medication (i.e., methylphenidate) prior to participating in the study. All participants were tested individually at their school or a clinic (testing time was approximately 45 to 60 minutes for each child) and seen only once by one of five investigators. Administration of tasks was counterbalanced to control for possible order effects. Tasks

Six executive functin tasks (comprising eight measures) and two nonexecutive function tasks (i.e., vocabulary) were used.

visual search. This task, previously adopted as an executivefunction task (Welsh, Pennington, \& Grossier, in press) required an organized search of a visual-stimulus display for a target item. Children were timed as they searched for a target interspersed among 
distractor stimuli, across eight trials. The dependent variable was an efficiency score calculated by dividing response time (in seconds) by the number of correct responses. Thus, lower values represented better efficiency.

Welsh et al. (in press) found that this task loaded most highly on a factor that was labeled, "speeded Response." No information was available regarding the reliability or validity for this task.

Verbal Fluency. This task required a systematic search of the semantic network. A semantic category (e.g., clothing) was presented orally to the child who was then required to say as many words within the semantic category as possible within a 40-second time interval. The categories were adapted from the McCarthy Scales of Children's Abilities (McCarthy, 1972), and included "food," "clothing," "animals," and "things to ride." The dependent variable was the total number of correct words produced across the four nonpractice categories.

Deficits on verbal fluency tasks have been found in adults with frontal lobe damage (Milner, 1964), as well as with children with PKU and $A D H D$ (Welsh et al., in press). Iimited information is currently available regarding the reliability and validity of this task. Gnys and willis (in press) reported a test-retest reliability coefficient of $\mathbf{7 4}$ for Verbal Fluency for young children, and a cross-validated convergent validity coefficient of .45 with a Tower of Hanoi task (described subsequently). The average split-half reliability of the General Cognitive Index from the McCarthy Scales of Children's Abilities is reported in the manual as .93. The average split-half reliability for the Verbal scale (which also includes this task) is reported as .88 (McCarthy, 1972).

Wisconsin Card Sorting Test (WCST, Berg, 1948). The wCST has been used widely as a measure of abstract reasoning and flexibility of thought and action (Lezak, 1984). Although adults with frontal lobe damage, as well as children with ADHD, have been found to perform poorly 
on the WCST, with performance characterized by inflexible, perseverative responding (e.g., Berg, 1948; Chelune et al., 1986) little information is available regarding the reliability and validity of this task. A set of four stimulus cards was placed on the table in front of each child, and each participant was give 64 cards on which were printed one of four symbols. The child was instructed to sort the cards individually, by placing them individually under one of the four stimulus cards. The investigator provided feedback after each card was sorted (i.e., "right" or "wrong"), and the participant was to deduce the correct rule based on the investigator's feedback. After the initial rule was learned by the participant, the investigator changed the rule without informing the participant. There were two dependent measures: (a) total number of errors and (b) total number of perseveration responses. The perservation score was determined by summing the number of responses that would have been correct in the immediately preceding stage. Continuation of incorrect responses prior to achieving the first category was also scored as perseveration.

Matching Familiar Figures Test (MFFT, Kagan, 1966). The MFFT is a visual task that requires visual search, hypothesis testing, and impulse control. The MFFT has been found to discriminate between normal children and children with $A D H D$, with regard to number of errors and speed of responding (Brown \& Quay, 1977; Kagan, 1964). The internal consistency has been reported to be .89 for mean latency and .62 for errors (Welsh et al., in press). Participants were shown a picture and instructed to find the identical match from among six similar pictures. Two practice trials and twelve test trials were administered to each participant. There were two dependent measures: (a) mean latency to first response in seconds and (b) total number of errors. Tower of Hanoi (Borys, Spitz, \& Dorans, 1982). The Tower of Hanoi, a ring-transfer task previously employed as a measure of planning (Simon, 1975; Welsh et al., in press), required participants to plan a 
sequence of moves in order to duplicate the investigator's model.

The examiner and child sat facing each other with identical Tower of Hanoi apparatuses placed in front of them. Each apparatus consisted of a rectangular base with three vertical dowels spaced $11.5 \mathrm{~cm}$ apart. Three colored rings (red, yellow, and blue) of three sizes (small, medium, and large, respectively) were placed on the investigator's far left dowel to begin the task. This arrangement represented the goal configuration that the child was required to achieve on all trials. The following rules applied to movement of the rings: (a) a larger ring could not be placed on a smaller ring, (b) only one ring could be moved at a time, and (c) each ring had to remain in a dowel or in the child's hand at all times (i.e., the child could not place a ring on the table or hold it with the other hand while moving a second ring). To simplify task explanation, instructions were presented under the guise of a monkey game (Klahr \& Robinson, 1981). All participants demonstrated understanding of the rules by repeating the rules orally, and by successfully completing two practice trials. Individuals translocations were recorded by the investigator. The dependent measure was the total number of points achieved, based on the number of trials required to complete the solution. Two consecutive correct trials of each problem were required in order to receive points. The possible score across the six, three-ring problems ranged from 0 to 36 . If the child correctly solved the final three-ring problem, an additional ring (intermediate size, orange) was presented. The possible score across three, four-ring problems ranged from 0 to 18. Thus, the total possible score on the Tower of Hanoi ranged from 0 to 54 .

Welsh et al. (in press) found that the Tower of Hanoi loaded most highly on a factor labeled, "planning." Again, limited information is currently available concerning the reliability or criterion-related validity for the task. As reported previously, Gnys and willis (in press) reported a reliability coefficient for Tower of Hanoi of .72 and 
a cross-validated convergent validity coefficient of .45 with Verbal Fluency.

Mazes (Wechsler Intelligence Scale for Children-Revised, 1974). This graphomotor task consisted of nine mazes of varying sizes and complexity, with scoring based on the number of errors committed in each maze. Test-retest reliability of Mazes has been reported to be .72 (Sattler, 1982). Mazes have been found to discriminate between adults with and without frontal lobe damage (Klebanoff, 1954; Smith, 1960). Participants were administered all nine mazes, and the dependent measure was the total number of points achieved, as determined by the wISC-R manual.

\section{Peabody Picture Vocabulary Test-Revised (PPVT-R, Form L, Dunn \&} Dunn, 1981). The PPVT-R is a receptive vocabulary test, consisting of 150 stimuli, each with four pictures. The investigator stated a word and the child was instructed to point to the picture most like the stimulus word. Points were obtained for correct responses, the total of which was used as the dependent variable. Basal and ceiling limits were determined according to instructions in the PPVT-R manual. The testretest reliability of the PPVT-R has been reported to be .73 and splithalf reliability coefficients range from .61 (at the 2-6 year level) to .88 (at the 18 year level) (Weiner, 1979). Children with receptive language deficits have been found to perform below expectations on the PPVT-R (Lezak, 1984). In the present study, the PPVT was included as a nonexecutive function measure, in order to help establish the discriminant validity of the executive function tasks.

Boston Naming Test (Kaplan, 1978). The Boston Naming Test, developed as a measure of expressive naming, consists of 85 pictures ranging in familiarity from common to uncommon. The investigator presented the pictures and the participant was instructed to name the picture. Scoring was based accurate naming of each picture. The test began with the first item for all participants, and was terminated after 
six consecutive incorrect responses. The Boston Naming Test was included in the present study as a second, nonexecutive function discriminant measure. 


\section{Chapter III}

\section{Results}

To test for possible group and age effects, and to explore the ability of tasks to discriminate among groups, multivariate analysis of variance (MANOVA), follow-up tests, and a discriminant function analysis were performed. There were eight tasks with a total of ten dependent variables: Visual Search, Verbal Fluency, Wisconsin Card sorting Test (two measures), Matching Familiar Figures Test (two measures), Tower of Hanoi, Mazes, Peabody Picture Vocabulary Test, and Boston Naming Test. To test the hypothesis that significant group and age differences would exist, a 3 by 3 between subjects factorial MANOVA was performed on the dependent variables. Independent variables were Group (ADHD, anguage Disorder, Nondisabled) and Age (Age Group $1=6$ to 7 years; Age Group $2=8$ to 9 years; Age Group $3=10$ to 12 years). Results revealed significant main effects for Group $(\underline{F}(20,194)=7.50, p<.001$, Wilks Lambda $=.318)$ and Age $(\underline{F}(20,194)=9.36, p<.001$, wilks Lambda $=$ .258 ), and a significant Group $x$ Age interaction was not found $(\underline{F}(20,194)=1.02$, Wilks Lambda $=.67)$. A strong association was found between Group and the combined Dependent variables $\left(\eta^{2}=.44\right)$, as well as Age and the combined dependent variables $\left(\eta^{2}=.49\right)$. Means, standard deviations, and results of univariate analyses of variance (ANOVA) are presented in Tables 1 through 6. Analyses indicated significant group differences on Peabody Picture Vocabulary Test, Boston Naming, Matching Familiar Figures Test (errors), Mazes, and Tower of Hanoi, and significant differences for Age on all measures except Matching Familiar Figures Test (mean latency). Except for visual search, Matching Familiar Figures Test (errors), Wisconsin Card Sorting Test (errors and perseveration), higher means are associated with better performance. 
Table 1

Means and Standard Deviations for Nondisabled and Clinical Groupg

Task

Executive Function Tasks

visual search

\begin{tabular}{|c|c|c|c|}
\hline$\underline{\mathrm{s}}$ & $\begin{array}{l}2.69 \\
1.67\end{array}$ & $\begin{array}{l}3.13 \\
1.31\end{array}$ & $\begin{array}{r}2.50 \\
.94\end{array}$ \\
\hline$s \bar{D}$ & $\begin{array}{l}35.66 \\
10.18\end{array}$ & $\begin{array}{l}32.08 \\
10.28\end{array}$ & $\begin{array}{r}34.77 \\
8.58\end{array}$ \\
\hline
\end{tabular}

Wisconsin Card sorting Test (Errors)
$\underline{\mathbf{M}} \underline{\underline{D}}$
51.50
51.64
55.13
25.59
25.18
20.92

wisconein card sorting Test

(Perseveration)
$\underline{\mathbf{M}}$

36.63

36.58

20.22

34.73

23.44

17.96

Matching Familiar Figures Test

(Errora) *
M
17.52
17.67
7.31
13.02
6.11

Matching Familiar Figures Test

(Mean Latency)
$M$
6.61
7.24
7.90
$\underline{\mathrm{SD}}$
3.75
3.80
4.83

Tower of Hanoi *

$\underline{\mathrm{S}} \overline{\mathrm{M}}$

26.61

27.55

10.78

32.91

9.33

8.99

Maze日*
$\mathbf{s} \overline{\mathrm{M}}$
16.00
4.08

18.41

5.00

17.31

3.87

Vocabulary Tagke

Peabody Picture Vocabulary Test*
M
$\underline{\mathbf{s}}$
106.77
17.71

B5. 58

102.93

17.90

16.43

Boston Naming Test*

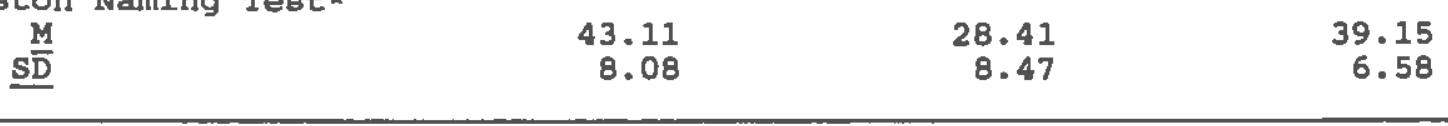


Table 2

ANovA Table for Peabody Picture Vocabulary Test

\begin{tabular}{lrrrrr}
\hline Source & DF & SS & MS & F & $\eta^{2}$ \\
\hline Group & 2 & 4548 & 2274 & $22.7{ }^{2}$ & .304 \\
Error & 106 & 10588 & 99 & & \\
\hline $\mathfrak{Q}<.001$ & & & & & \\
\hline
\end{tabular}

Table 3

ANoVA Table for Bogton Naming Test

\begin{tabular}{lrrrrr}
\hline Source & DF & SS & MS & $F$ & $\eta^{2}$ \\
\hline Group & 2 & 2800 & 1400 & $44.7 *$ & .457 \\
Error & 106 & 3319 & 31 & &
\end{tabular}

* $2<.001$

Table 4

ANOVA Table for Matching Familiar Figures Test-Errors

\begin{tabular}{lrrrrr}
\hline Source & DF & SS & MS & F & $\eta^{2}$ \\
\hline Group & 2 & 468 & 234 & $6.0 *$ & .103 \\
Error & 106 & 4092 & 38 & &
\end{tabular}

$* \mathrm{p}<.03$ 
Table 5

ANOVA Table for Maze日

\begin{tabular}{lrrrrr}
\hline Source & DF & SS & MS & F & $\eta^{2}$ \\
\hline Group & 2 & 1187 & 593 & $5.53 *$ & .095 \\
Error & 106 & 43415 & 409 & & \\
\hline $\mathrm{P}<.05$ & & & & & \\
\hline
\end{tabular}

Table 6

ANOVA Table for Tower of Hanoi

\begin{tabular}{|c|c|c|c|c|c|}
\hline Source & DF & ss & MS & $\mathbf{F}$ & $\eta^{2}$ \\
\hline Group & 2 & 794 & 397 & $6.7 *$ & .112 \\
\hline Error & 106 & 6289 & 59 & & \\
\hline
\end{tabular}


Follow-up Tests

Planned comparisons of group differences were conducted using the Tukey test. Tukey comparisons of Group (ADHD, Language Disorder, Nondisabled) revealed that nondisabled participants performed significantly better than children with ADHD and children with Developmental Language Disorder on two executive function tasks Matching Familiar Figures Test (errors) and (b) Tower of Hanoi, and that children with ADHD performed significantly poorer than children with Developmental Language Disorder on Mazes. There were no significant differences between children with ADHD and Language Disorder on Matching Familiar Test (errors) or Tower of Hanoi, however, suggesting that the clinical groups performed equally poorly on these two measures.

Significant differences also were found between children with Developmental Language Disorder and the two other groups on the two nonexecutive function tasks, Peabody Picture Vocabulary Test, and the Boston Naming Test, with the Language Disorder group performing significantly more poorly than Nondisabled children and the ADHD groups.

Tukey comparisons of Age also were conducted in order to isolate age-related differences in performance across the dependent measures. Results are summarized in Table 7 , revealing significant differences across the three age groups on the Peabody Picture Vocabulary Test, Boston Naming Test, Verbal Fluency and Tower of Hanoi, with increasing age associated with improved performance. On the Matching Familiar Figures Test (errors), Mazes, and Wisconsin Card Sorting Test (error and perseveration measures) no significant differences were found between children in the first two age groups.

To examine the shape of the relationship between Age and the ten dependent variables, trend analysis was conducted. The relationship was found to be linear for all tasks. A significant quadratic component was not found for any of the tasks. 
Table 7

Means and Standard Deviations for Age Groups 6-7, 8-9, and 10-12

Age Group

Tasks

$\begin{array}{ccc} & \text { Age Group } & \\ \text { I } & \text { II } & \text { III }\end{array}$

visual search

M

$\overline{\bar{S}} \mathrm{D}$

\subsection{2}

.22

Verbal Planning

M

$\underline{\bar{s} D}$

26.84

1.19

34.46

1.04

42.38

2.24

Wisconsin Card

Sorting Test

(errorg)

$\mathbf{M}$

$\overline{\mathrm{S}} \mathrm{D}$

65.51

.80

41.98

1.68

38.91

3.94

Matching Familiar

Figures Test

(errors)

M

$\overline{\mathrm{SD}}$

19.27

2.04

16.91

2.35

Matching Familiar

Figures Test

(mean latency)

$M$

$\underline{\mathrm{SD}}$

Tower of Hanoi

$\mathrm{M}$

$\overline{\mathrm{S} D}$

Mazes

$M$

$\overline{\mathrm{SD}}$

13.67

.88

6.75

1.42

.76

23.73

3.66

29.20

5.24

Peabody Picture

Test

$\underline{\mathrm{M}} \mathrm{D}$

83.34

8.80

99.38

5.05

117.73

Boston Naming Test

$\underline{\mathrm{M}} \mathrm{D}$
30.40
5.79
36.72

5.82
23.21

4.20

11.06

1.66

8.66

36.42

2.06

6.73
19.90

1.84
33.52
6.47 .69

44.46

4.61 
In summary, results of Tukey comparisons revealed significant differences among groups on three executive function measures (Matching Familiar Figures Test (errors), Mazes, and Tower of Hanoi), with the nondisabled group differing from the two clinical groups on Matching Familiar Figures Test (errors) and Tower of Hanoi. No significant differences were found between children with ADHD and Language Disorder on these two measures. Analyses also revealed significant differences between the Language Disorder group and the other two groups on the Peabody Picture Vocabulary Test and Boston Naming Test, but no significant differences were found between the nondisabled or ADHD groups on these measures (see Figure 1). Finally, follow-up tests indicated age-related changes for both the nonexecutive function tasks (Boston Naming Test and Peabody Picture Vocabulary Test) and three of the executive function measures (Verbal Fluency, Visual Search, and Tower of Hanoi). On the remaining measures, no significant differences were found between the first two age groups.

Discriminant Function Analysis

To test the hypothesis that the dependent variables combined would be able to predict group membership, a direct discriminant function analysis was performed. Predictor variables included the ten dependent variables described previously. Two discriminant functions were calculated, with a combined $\left.\chi^{2}(22)=127.35, \mathrm{p}<.001\right)$. After removal of the first function, discriminating power remained significant $\chi^{2}(10)$ $=27.344, p<.003$. The two discriminant functions, accounted for approximately 598 and $22 \%$ of the between-group variance, respectively.

As shown in Figure 2, the first discriminant function discriminated children with ADHD from children with Developmental Language Disorder and the nondisabled comparison group. The second discriminant function discriminated nondisabled children from the ADHD and Developmental Language Disorder groups. 


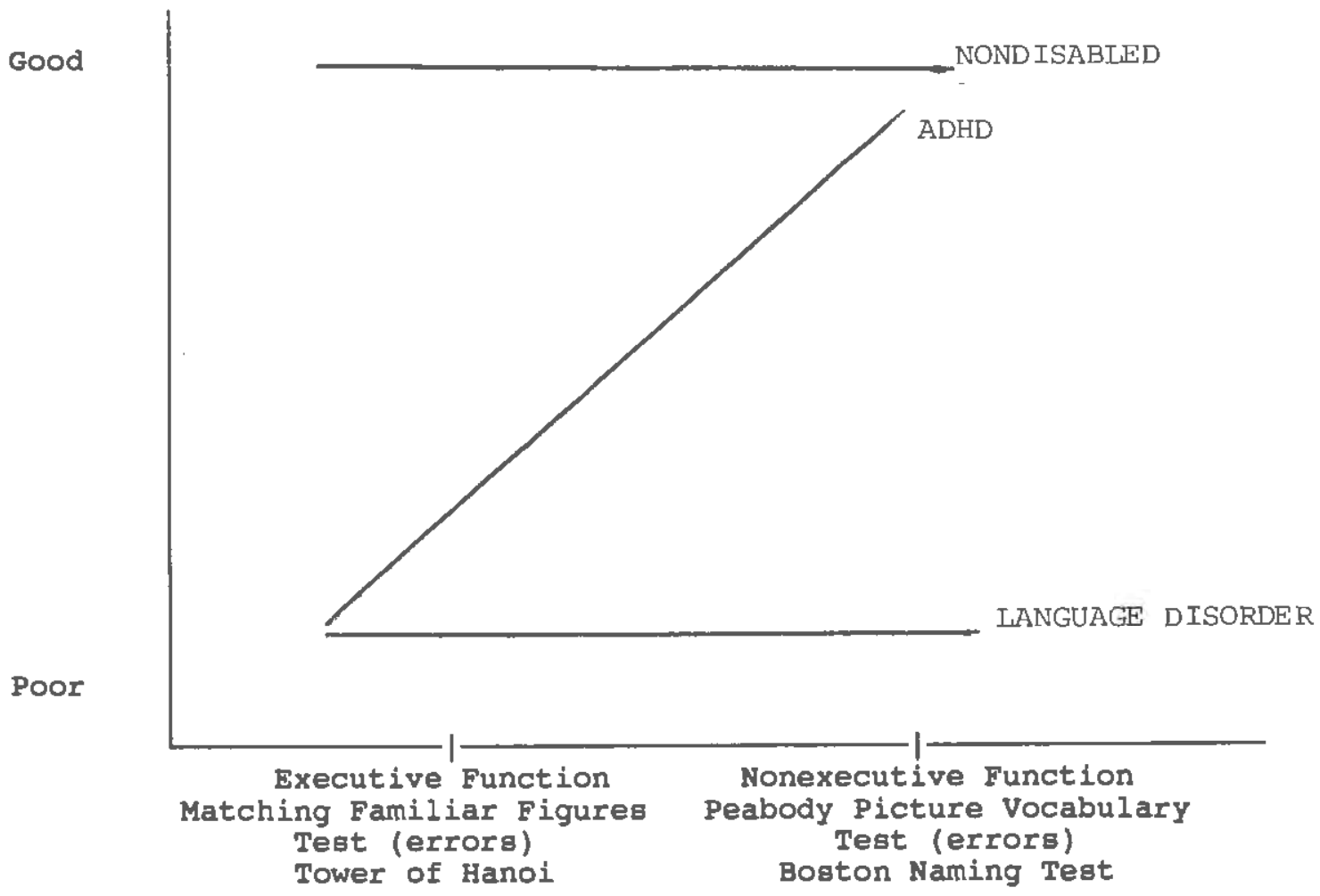

Figure 1. Conceptual view of group performance on executive function and nonexecutive function taska. 


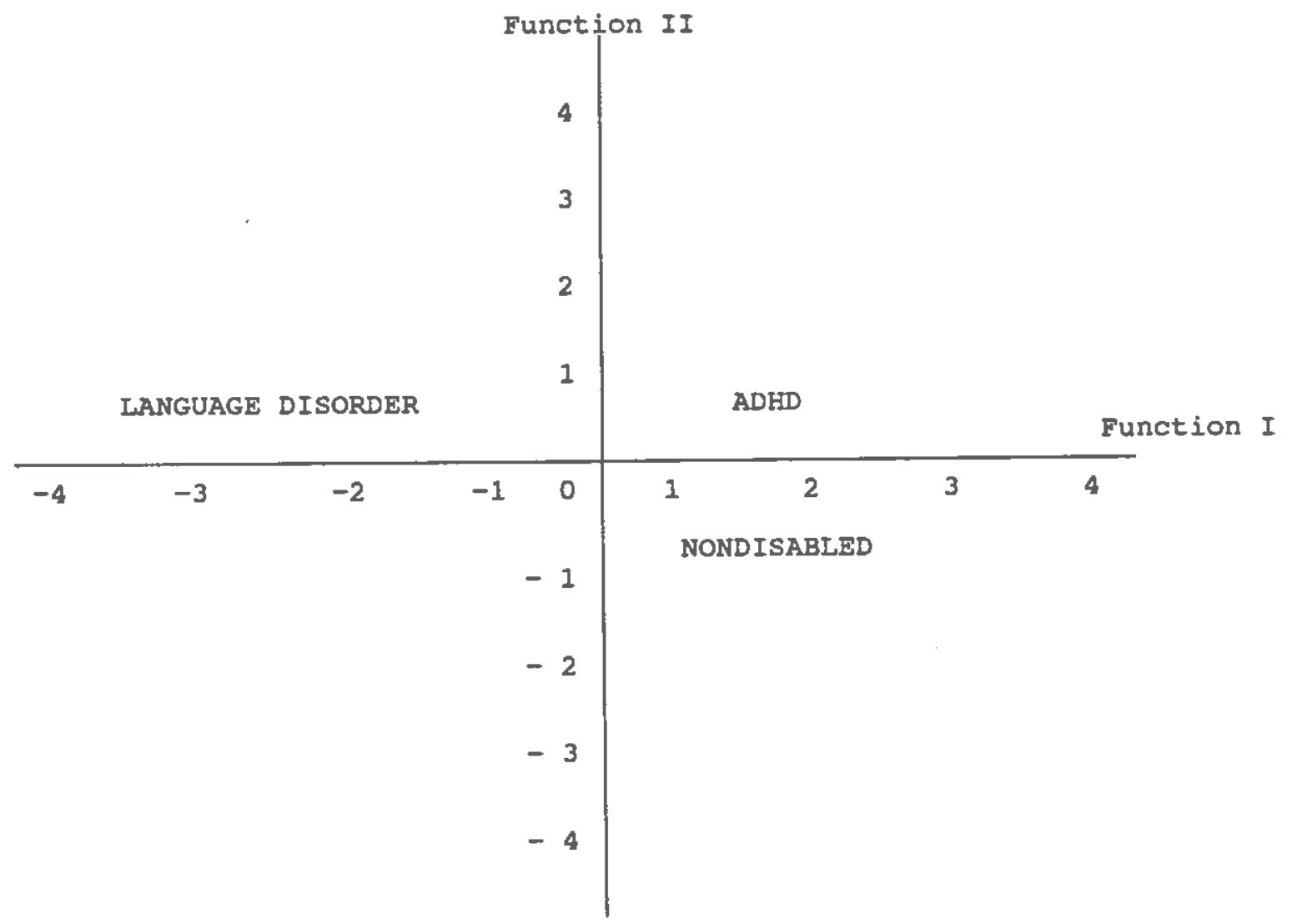

Figure 2. Discriminant functions distinguishing between children with $A D H D$ and language disorder, and between nondibabled and clinical groups. 
A structure matrix of correlations between predictor variables and discriminant functions, as seen in Table 8 , suggested that the primary variables distinguishing between children with ADHD and children with Developmental Language Disorder (firat function) were the Boston Naming Test $(r=.63)$ and the Peabody Picture Vocabulary Test $(r=.41)$. The variables contributing most to the second discriminant function, discriminating the nondisabled from the two clinical groups were the Matching Familiar Figures Test (errors) $(r=.58)$ and the Tower of Hanoi $(r=.55)$.

Overall classification results are presented in Table 9. These results indicated that 77.48 of the cases were correctly classified, significant at the $p<.001$ level, representing a 638 improvement over expected classification by chance (Huberty, 1984; willis, 1984). The predicted group membership for the children with ADHD was 67\% (a 518 improvement over chance), with 31 misclassified as nondisabled children, and 3\% as Language Disorder. The predicted group membership for the Language Disorder group was 88\% (an 83\% improvement over chance), with 98 misclassified ad $A D H D$ and 38 as nondisabled. The predicted group membership for the nondisabled group was $78 \%$ (a 648 improvement over chance), with 11 \% equally clasaified as ADHD and Language Disorder. 
Table 8

Structure Matrix of Correlations Between Predictor Variables and

Discriminant Functions

Taвk

Function I

Function II

Visual Search

$-.113$

.211

Verbal Fluency

.123

$-.009$

Wisconsin Card

Sorting Test

(errors)

.013

$-.134$

Wisconsin Card

Sorting Test

(perseveration)

$-.020$

.050

Matching Familiar

Figures Teat

(errors)

$-.072$

Matching Familiar

Figureg Test

(mean latency)

$-.023$

$-.233$

Tower of Hanoi

.030

$-.554$

Mazes

$-.169$

$-.131$

Peabody Picture

Test

$-.015$

Boston Naming Test

.632

$-.015$ 
Table 9

Claseification Accuracy Table

\begin{tabular}{|c|c|c|c|c|}
\hline \multirow[b]{2}{*}{ Group } & \multirow[b]{2}{*}{$\mathbf{n}$} & \multicolumn{3}{|c|}{ Predicted Group Membership } \\
\hline & & ADHD & Language Disorder & Nondisabled \\
\hline ADHD & 36 & $66.7 \%$ & 2.88 & 30.68 \\
\hline Language Disorder & 34 & 8.88 & 88.28 & 2.98 \\
\hline Nondisabled & 45 & 11.18 & 11.18 & 77.88 \\
\hline
\end{tabular}




\section{Chapter IV}

Discussion

The purposes of the present study were (a) to investigate the performance of three groups of children: those diagnosed with ADHD, those diagnosed with Developmental Language Disorder, and a group of nondisabled matched comparison children on a battery of neuropsychological tasks purported to measure executive function in children, and (b) to investigate the construct validity of tasks used to measure executive function across three age levels. It was hypothesized that (a) the ADHD group would perform more poorly than children with Developmental Language Disorder or the nondisabled group across the measures or executive function, (b) the Language Disorder group would perform more poorly than either the ADHD group or the nondisabled group on the measures of nonexecutive function, (c) group performance would reflect age-related changes in executive function performance with all three groups evidencing improved performance with increasing age, (d) a linear composite of the executive function and nonexecutive function tasks would discriminate among the ADHD, Language Disorder, and nondisabled groups.

\section{Group Differences}

Results supported the hypothesis that significant group differences would exist on measures of executive function, with (a) children with ADHD and children with Developmental Language Disorder performing significantly more poorly than nondisabled children on two measures of executive function (Matching Familiar Figures Test (errors) and Tower of Hanoi), and (b) children with ADHD performing significantly more poorly than children with Developmental Language Disorder on one other measure of executive function (Mazes). Results also supported the hypothesis that children with Developmental Language Disorder would perform significantly more poorly than children with ADHD and nondisabled children on the nonexecutive function measures (Peabody 
Picture Vocabulary Test - Revised and Boston Naming). With regard to the Matching Familiar Figures Test (errors), results of the present study are consistent with numerous investigations that have demonstrated significant differences in performance between children with ADHD and matched controls (e.g., Kagan, 1964; Rapport, DuPaul, Stoner, \& Jones, 1986).

Previous research (e.g., Passler et al., 1985; Welsh et al., 1990) has indicated that tasks of executive functioning are not isomorphic. The fact that Mazes was found to be the only one of eight executive function measures to discriminate between the clinical groups included in the present study should be explored further. For example, Mazes differs from the Matching Familiar Figures Test and Tower of Hanoi in several ways (e.g., graphomotor aspects, memory components) and it is reasonable to speculate that children with $A D H D$ may differ from other clinical subgroups only in terms of particular aspects of executive functioning. Such speculation, of course, is subject to empirical investigation.

Contrary to expectations was the lack of significant group differences on Verbal Fluency, Visual Search, Matching Familiar Figures Test (mean latency), and Wisconsin Card Sorting Test (errors and perseveration). These findings are inconsistent with those reported by Chelune et al. (1986) and Boucugnani and Jones (1989), who found significant differences between children with ADHD and matched controls on number of errors and number of perseverative responses on the Wisconsin Card Sorting Test. Present findings also are inconsistent with Felton, Wood, Brown and Campbell (1989) who reported significant differences between children with ADHD and a matched comparison group on a verbal fluency task similar to the Verbal Fluency task used in the present study. Failure to find group differences on the Wisconsin Card Scoring Test (errors and perseveration) and Verbal Fluency task, however, is supportive of research conducted by McGee et al. (1989) and 
Fischer et al. (1990) who did not find significant differences between adolescents with $\mathrm{ADHD}$ and a normal comparison group. There are a variety of possible explanations for the equivocal findings of course. For example, the present findings could suggest that (a) executive function deficits are not characteristic of children with ADHD, or alternatively, (b) that the tasks used in the present study were not valid measures of the executive function construct. Clearly, discrepancies exist in the literature that warrant further investigation. These discrepancies may in part be due to differences in diagnostic and inclusion criteria, SES, unstandardized tasks, psychometric properties of tasks, sample size, and the heterogeneous nature of the executive function construct. The present study attempted to address these issues by employing stringent diagnostic and inclusion criteria, matching participants for age, using standardized instructions, and including an adequate number of participants based on a priori statistical power analyses, and using multiple measures of executive functioning.

\section{Age-Related Changes}

The third hypothesis, that group performance would reflect agerelated changes in executive function performance with all three groups evidencing improved performance with increasing age, also was supported. Significant linear (but not quadratic) trends were found for all tasks used in the study (collapsed across group). Results indicated that children in the third age group (10-13) performed significantly better than children in the second age group (8-9), who in turn performed significantly better than children in the first age group (6-7) on the Peabody Picture Vocabulary Test - Revised, Boston Naming, Verbal Fluency, and Tower of Hanoi. On the Matching Familiar Figures Test (errors), Wisconsin Card Sorting Test (errors and perseveration), and Mazes, children in the third age group (10-13) performed significantly better than children in the first and second age groups (who did not 
differ significantly from each other).

These results are consistent with previous research (e.g., Becker et al., 1988; Passler et al., 1985; and Welsh et al. 1990), that has reported age-related changes associated with executive function measures. Welsh et al. (in press), for example, reported significant gains in performance of children age 10 to 13 , relative to younger children on Visual Search, Verbal Fluency, Wisconsin Card Sorting Test (perseveration), Matching Familiar Figures Test (errors and mean latency), and Tower of Hanoi. Present findings are inconsistent with Welsh et al. (in press), however, in that adult level performance (as defined in that study) was not attained by any group on Visual search, Matching Familiar Figures Test (errors), or the wisconsin Card Sorting Test (perseveration). Welsh et al. reported adult level performance was attained on these measures by normal children by age 6 (Visual Search and Matching Familiar Figures Test) and 10 years (Wisconsin Card Sorting Test). Present findings also are inconsistent with welsh et al. with respect to the age at which adult level performance was achieved on the Tower of Hanoi. According to Welsh et al., adult level performance was attained by normal children by six years. In the present study, adult level performance was attained by children with ADHD by age 10 to 12 years, and nondisabled children and children with Developmental Language Disorder by age 8 to 9 years.

Although differences have emerged between previous research and the present study with respect to tasks employed as measures of executive function, as well as differences in specific age-related changes in task performance, convergence can be seen in the literature with regard to the relationship between age and task performance. specifically, younger children do not perform as well on tasks presumed to measure organized search, ability to inhibit inappropriate responding, flexibility of thought and action, and planning, as older children. Further, the age at which adult level performance is 
achieved, varies according to the nature of the task. Theoretically, these results support previous research (e.g., Passler et al., 1985) that suggests that performance on one task presumed to measure some aspect of executive functioning, should not necessarily be expected to predict the level of performance on some other task of executive functioning.

\section{Discriminant Analysis}

The fourth hypothesis, that the executive and nonexecutive function tasks combined would discriminate among the ADHD, Language Disorder, and Nondibabled groups, also was supported. specifically, results revealed that 778 of the children were correctly clasified, representing a 638 improvement over chance. The discriminant analysio was most successful at predicting group membership for children with Developmental Language Disorder (888 correctly classified), followed by Nondisabled children (78\% correctly classified) and children with ADHD (67\% correctly classified). Of those children with ADHD who were misclassified, $30 \%$ were classified as nondisabled and 38 as Language Disorder. of those children with Developmental Language Disorder who were misclassified, 98 were classified as $A D H D$, and 38 as Nondisabled. These results are similar to those found by Kuehne, Kehle, and McMahon (1987) who reported that among nondisabled children, children with ADHD, and children with specific Learning Disabilities, the majority of children misclassified were classified as nondisabled. Chelune et al. (1986) and Boucugnani and Jones (1989), compared the performance of children with ADHD and nondisabled children on the wisconsin card sorting Test, and reported overall classification rates of 858 and $78 \%$, respectively. Thus, current results support previous research that has demonstrated that children with ADHD can be distinguished from other groups of children, based on performance on executive function and nonexecutive function tagks, 
Double Dissociation

The construct validity of the executive function tasks was assessed using a double dissociation paradigm. It was predicted that children with $\mathrm{ADHD}$ and nondisabled children would show high levels of performance on the nonexecutive function tasks (Peabody Picture Vocabulary Test and Boston Naming) relative to the Developmental Language Disordered children and nondisabled children. Results supported previous research (e.g., Chelune et al. 1986) indicating that children with ADHD performed significantly more poorly than nondisabled children on executive function tasks. The present study failed, however, to reveal a clear double dissociation. Although children with Developmental Language Disorder performed significantly more poorly than nondisabled and $\mathrm{ADHD}$ children on the nonexecutive function (i.e., vocabulary) tasks, children with Developmental Language Disorder performed significantly better than children with ADHD on only one of the eight executive function measures. Thus, the present findings suggest that executive function deficits may not necessarily be unique to ADHD, but may be characteristic of other child clinical populations as well. Clinically, results also suggest that although measures of executive function are useful in the evaluation of ADHD, they may not be sufficient.

A plausible theoretical interpretation of the present findings is that, contrary to traditional views, many executive functions may be subordinate to language-related skills. In other words, if language deficits exist, deficits in executive functions would follow. Executive function deficits, however, could exist in the presence of intact language-related skills. Given the literature that espouses a physiological explanation of learning disorders (including languagerelated disorders), such an interpretation is consistent with Luria's (1980) and Vygotsky's (1960) views of functional systems and ontogenetic development. According to Luria (1980), dysfunctions that occur during 
early ontogenetic stages, may have deleterious effects on higher-order cognitive processes. Thus, it could be hypothesized that the frontal lobe systems that are associated with language, develop before those prefrontal systems associated with higher-order cognitive processes such as executive functions. Consequently, any disturbance in the development of language-related systems, as is presumed by some to occur in language disorders, would theoretically result in higher-order executive function deficits. Children without language-related disorders, however, conceivably could exhibit executive function deficita.

Other interpretations of courge are plausible. For example, perhaps the methods used to asgess executive functions were inadequate measures of the construct. Little information is available regarding the psychometric properties of many of the tasks included as measures of executive function, hence the reliability and validity of the measures should be questioned.

A second alternative is that the ADHD group was cognitively more advanced than the Developmental Language Disorder and Control groups, as suggested by a slightly better performance $(p<.05)$ on the Ravens Progressive Coloured Matrices (Raven, 1965) (Means = 28, 23, and 25 for ADHD, Developmental Language Disorder, and nondisabled Groups, respectively). This interpretation appears unlikely, however, given the small proportion of variance accounted for by the group effect (118), and the relatively high standard error of measurement for this instrument. Additionally, a one-way multivariate analysis of covariance (MANOVA) was conducted for Group, using Ravens as a Covariate across the ten dependent measures. Reeulte of the interaction were not significant, and the regression slopes therefore, were assumed to be comparable across groups. Results of the MANCOVA were identical to reaults of the MANOVA which were reported previously. 
A third alternative is that the Developmental Language Disordered group may have consisted of subjects with multiple disorders such as anxiety disorder, depression, conduct disorder, or ADHD. A study by Frost, Moffitt, and McGee (1989) compared the performance of children with single, multiple, and no disorders on a series of neuropsychological tasks, including three executive function tasks (Verbal Fluency, WCST, and Mazes). Results indicated that children with multiple disorder performed significantly more poorly on executive function taske relative to children with single dieorders (e.g., ADHD) and controls. In the present study, attempts were made to identify and gubsequently to exclude children with Developmental Language Disorder who were suspected of having behavioral or emotional difficulties, however, no objective criteria (e.g., rating scale) were used. Thus, comorbidity is a potential confounding influence in the present study. In conclusion, the results of the present study support previous regearch indicating that children with ADHD perform Bignificantly more poorly on tasks of executive function relative to nondisabled children. The results further indicate, however, that executive function deficits may not be unique to $A D H D$, but may be characteriatic of other child clinical populations. The present study is among the first to use a double dissociation paradigm to asses the construct validity of tasks designed to measure executive functioning. Future research needs to evaluate further the psychometric properties of such tasks, and to determine whether executive function deficits are characteristic of other child clinical populations. 


\section{Bibliography}

American Psychiatric Association. (1980). Diagnostic and Statistical Manual of Mental disorders (3rd Ed). Washington, DC: American Psychaitric Association.

American Psychological Association. (1981). Ethical principles of psychologists (revised). American Psychologist, 36, 633.638. Beaumont, L.G. (1983). Introduction to Neuropsychology. New York: Guilford Press.

Becker, M.G., Isaac, W., \& Hynd, G. (1988). Neuropsychological development of nonverbal behaviors attributed to frontal lobe functioning. Developmental Neuropsychology, $3,275-298$.

Berg, E.A. (1948). A simple objective test for measuring flexibility in thinking. Journal of General Psychology, 39, 15-22.

Bianchi, L. (1922). The mechanism of the brain and the function of the frontal-lobes. Edinburgh, Scotland: Livingstone.

Bolter, J.F., \& Long, C.J. (1985). Methodological issues in research developmental neuropsychology. In L.C. Hartlage and C.F. Telzrow (Eds.), The neuropsychology of individual differences: A

developmental perspective. New York: Plenum. Borys, S.V., Spitz, H.H., \& Dorans, B.A. (1982). Tower of Hanoi performance of retarded and non-retarded students. American Journal of Mental Deficiency, 84, 280-288.

Boucugani, L.L. \& Jones, R.W. (1989). Behaviors analagous to frontal lobe dysfunction in children with attention deficit hyperactivity disorder. Archives of Clinical Neuropsychology, $4,161-173$. Cantwel1, D.P., \& Carlson, G.A. (1978). Stimulants. In J. Werry (Eds.), Pediatric psychopharmacology. New York: Brunner/Mazel. Chelune, G.J., Ferguson, W., Koon, R., \& Dickey, T.O. (1986). Frontal lobe disinhibition in attention deficit disorder. Child Psychiatry and Human Development, 16, 221-234. 
Conners, C.K. (1979). A teacher rating scale for use with drug studies in children. American Journal of Psychiatry, 126, 884-888. Damasio, A.R. (1985). The frontal lobes. In K.M. Heilman and Valenstein (Eds.), Clinical Neuropsychology. New York: Oxford University Press.

Denkla, M.B., \& Rudel, R.G. (1978). Anomolies of motor development in hyperactive boys. Annals of Neurology, $3,231-233$.

Diamond, A., \& Goldman-Rakic, P.S. (1985). Evidence for involvement of prefrontal cortex in cognitive changes during the first year of life: Comparison of human infants and rhesus monkeys on a detour task with transparent barrier. Neurosciences Abstracts, 11, 832 . Diamond, A., Zola-Morgan, S., \& Squire, L.R. (1987). Performance of monkeys with hippocampal ablations on Piaget's AB task. Neurosciences Abstracts, 13, 207.

Diamond, A. (1988). Differences between adult and infant cognition: Is the crucial variable presence or absence of language? In $\mathrm{L}$. Weiskrantz (Eds.)., Thought without language. New York: Oxford University Press.

Drewe, E.A. (1974). The effect of type and area of brain lesion on Wisconsin Card Sorting Test performance. Cortex, 10, 159-157. Dunn, L.M., \& Dunn, L.M. (1981). Peabody Picture Vocabulary TestRevised. Circle Pines, MN: American Guidance Service. DuPaul, G. (1990). (under review). The ADHD Rating Scale. Normative date, reliability, and validity. University of Massachusetts Medical Center: Worcester, MA.

Felton, R.H., Wood, F.B., Campbell, S.D. (1989). Separate verbal memory and naming deficits in attention-deficit disorder and reading disability. Brain and Language, 31, 171-184. 
Fischer, M., Berkley, R.A., Edelbrock, C.S., \& Smalliвh, L. (1990). The adolescent outcome of hyperactive children diagnosed by research criteria Journal of Consulting and Clinical Peychology, 58, 580588 .

Fletcher, J.M, Taylor, H.G. (1984). Neuropsychological approaches to children: Toward a developmental psychology. Journal of Clinical Peychology, 6, 39-56.

Frost, L.A., Moffitt, T.E., \& McGee, R. (1989). Neuropeychological correlates of psychopathology in a unselected cohort of young adolescents. Journal of Abnormal Psychology, 98, 302-313.

Fuster, J.M. (1973). Unit activity in prefrontal cortex during delayed-response performance: Neuronal correlates of transient monkey. Journal of Neurophygiology, 36, 61-78.

Fuster, J.M. (1980). The prefrontal cortex. New York: Raven.

Golden, C.J. (1981). A standardized version of Luria's neuropsychological tests. In S. Filskov \& T.J. Boll (Eds.), Handbook of clinical Neuropsychology. New York: Wiley Inter

Golden, C.J. (1981). The Luria Nebraska Children's battery: Theory and formulation. In G.W. Hynd \& J.E. Obrzut (Eds.). Neuropsychological assessment of the school-aged child. NY: Grune stratton.

Goldman, P.D., \& Naata, W.J.H. (1977). An intricately patterned prefrontocaudate projection in the rhesus monkey. Journal of Comparative Neurology, 27, 291-304.

Goyette, C.H., Conners, C.R., \& Ulrich, R.F. (1978). Normative data for Revised Conner Parent and Teacher Rating Scales. Journal of Abnormal Child Paychology, 6, 221-236.

Gnys, L., \&illis, W.G. (In press). Validation of executive function tasks with young children. Developmental Neuropsychology. 
Hynd, G.w., Semrud-Clikeman, M., Lorys, A., Norey, E.S., \& Eliopulus, D. (1990). Brain morphology in developmental dyslexia and attention deficit disorder/hyperactivity. Archives of Neurology, 47, 919-926. Hynd, G.W., Semrud-Clikeman, M., Lorys, A., Norey, E.S., Eliopulus, D., \& Lyytiner, H. (1990). Corpus callasum morphology in ADHD: Morphomenic analysis of MRI. Journal of Learning Disabilities, 24, 141-146.

Huberty, C.J. (1984). Issues in the use and interpretation of discriminant analysis. Psychological Bulletin, 1, 156-171. Hudson, M.T. (1991, March). A Pediatric perspective of attention deficit disorder. Paper presented at the National Association of School Psychologists, Dallas, TX.

Jones, G.V. (1983). On double dissociation of function.

Neuropsychologia, 21, 397-400.

Jones-Gotman, M., \& Milner, B. (1977). Design fluency: The invention

of nonsense drawings after frontal cortical lesions. Neuropsychologia, 15, 653-674.

Kagan, J. (1966). Reflection-Impulsity: The generality and dynamics of conceptual tempo. Journal of Abnormal Psychology, 71, 17-24. Kaplan, E.F. (1978). The Boston Naming Test. Boston: E. Kaplan and H. Goodglass.

Klebanoff, S.G. (1954). Psychologicval changes in organic brain lesions and ablations. Psychological Bulletin, 42, 585-623. Kopp, C.B. (1982). Antecedents of self-regulation: A developmental perspective. Developmental Psychology, 18, 194-214.

Kuehne, C., Kehle, T.J., \& McMahon, w. (1987). Differences between children with attention deficit disorder, chidren with specific learning disabilities, and normal children. Journal of school Psychology, 25, 161-166. 
Lezak, M.D. (1973). Neuropsychological Assessment. New York: Oxford University Press.

Lou, H.C., Henriksen, L., \& Bruhn, P. (1984). Focal cerebral hypoperfusion in children with dysphasia and/or attention deficit disorder. Archives of Neurology, 41, 825-829.

Luria, A.R. (1966). Higher cortical functions in man. New York: Basic Books.

Luria, A.R. (1972). The man with a shattered world. New York: Basic Books.

Luria, A.R. (1973). The working brain. New York: Basic Books. Mattes, J.A. (1980). The role of frontal lobe dysfunction in hyperkinesis. Comprehensive Psychiatry, 21, 358-368. McGee, R., Williams, S., Moffitt, T., \& Anderson, L. (1989). A comparison of 13 year-old boys with attention deficit disorder and/or reading disorder on neuropsychological measures. Journal of Abnormal Child Psychology, 17, 37-53.

Milner, B. (1964). Some effects of frontal lobectomy in man. In J.M. Warren \& $\mathrm{K}$. Akert (Eds.), The frontal granular cortex and behavior. New York: McGraw-Hill.

Nauta, W.J.H., (1971). The problem of the frontal lobe. Journal of Peychiatric Research, $\underline{8}, 167-187$.

Niki, H. (1974). Prefrontal activity during delayed alternation in the monkey in relation to direction of response. Brain Research, $\underline{68}$, 186-196.

Pandya, D.N., Dye, P., \& Kuyppers, H.G. (1969). Efferent corticocortical projections in the monkey. Brain Research, 13, 13. Passler, M.A., Isaac, W., \& Hynd, G.W. (1985). Neuropsychological development of behavior attributed to frontal lobe functioning in children. Developmental Neuropsychology, $1,349-370$. 
Petrides, M., \& Milner, B. (1982). Deficits on subject-ordered tasks after frontal and temporal lobe lesions in man. Neuropsychologia, 20, 249-262.

Rapport, M.D., DuPaul, G.Y., Stoner, G., \& Jones, I.T. (1986). Comparing classroom and clinic measures of attention deficit disorder: Differential, idiosyncratic, and dose-response effects of methylphenidate. Journal of Consulting and Clinical Psychology, 54, 334-341.

Raven, J.C. (1965). Guide to using the Coloured Progressive Matrices. NY: Psychological Corportation.

Ross, S.B. (1979). The central stimulatory action of inhibitors of dopamine uptake. Life Sciences, 24, 159-168. Satterfield, J.H., \& Cantwell, D. (1974). Pathophysiology of the hyperactive child syndrome. Archives of General Psychiatry, 31 , 839-844.

Shallice, T. (1982). Specific impairments of planning. In D.E. Broadbent \& L. Weiskrantz (Eds.), The neuropsychology of cognitive function. London: Royal Society.

Shaywitz, S.E., \& Shawitz, B.A. (1984). Diagnosis and management of attention deficit disorder: a pediatric perspective. Pediatric Clinics of North America, 31, 429-457.

Stuss, D.T., \& Benson, F. (1984). Neuropsychological studies of frontal lobes. Psychological Bulletin, 95, 3-28.

Voller, K.K.s. (1986). Right hemisphere deficit syndrome in children. American Journal of Psychiatry, 143, 1004-1009. Wechsler, D. (1974). Wechsler Intelligence Scale for Children Revised. New York: Psychological Corporation.

Welsh, M.C., \& Pennington, B.F. (in press). Assessing frontal lobe function in children: Views from developmental psychology. 
Welsh, M.C., Pennington, B.F., Ozonoff, S., Rouse, B., \& McCabe, E. (under review). Neuropsychology of early-treated PKU: specific executive function deficits.

Welsh, M.C., Pennington, B,F., \& McCabe, E. (1987). Performance of preschool PKU children on prefrontal measures. Journal of Clinical and Experimental Neuropsychology, $9,28$.

Welsh, M.C., Pennington, B.F., \& Grossier, B.B. (in press). A normative-developmental study of executive function: A window on prefrontal function in children. Developmental Neuropsychology. Welsh, M.C., Pennington, B.F., Ozonoff, S., Rouse, B., \& McCabe, E.R.B. (1990). Neuropsychology of eraly treated phyeylketonuria: specific executive function deficits. Child Development, 61, 1697-1713. Welsh, M.C., Wall, B.M., \&owle, P.O. (1989, April). Executive function in children with attention deficit disorder: Implicatios for a prefrontal hypothesis. Paper presented at the society for Reserach in Child Development, Kansas City, Mo. Wender, P. (1971). Minimal brain dysfunction in children. New York: Wiley Interscience.

Wigg, E., \& Samel-Mintz, E. (1982). Clinical Evaluation of Language Functioning. Columbus Ohio: Charles Merrill. Willis, W.G. (1984). Reanalysis of an actural approach to neuropsychological diagnosis and consideration of base rates. Journal of Consulting and Clinical Psychology, 52, 567-569. Zametkin, A.Y., and Cohen, R.M. (1990). Cerebral glucose metabolism in adults with hyperactivity of childhood onset. The New England Journal of Medicine, 323, 1361-1366. 